\title{
The complete chloroplast genome of the Jerusalem artichoke (Helianthus tuberosus L.) and an adaptive evolutionary analysis of the ycf2 gene
}

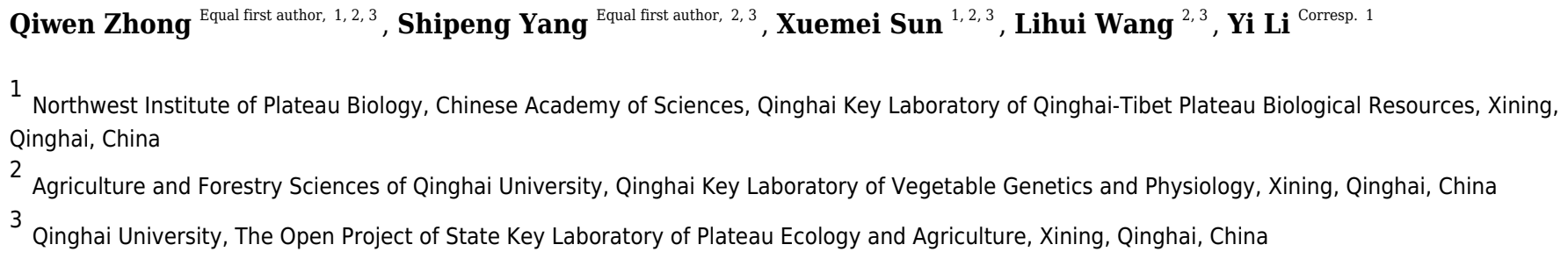

Jerusalem artichoke (Helianthus tuberosus L.) is widely cultivated in Northwest China, and it has become an emerging economic crop that is rapidly developing. Because of its elevated inulin content and high resistance, it is widely used in functional food, inulin processing, feed, and ecological management. In this study, Illumina sequencing technology was utilized to assemble and annotate the complete chloroplast genome sequences of Jerusalem artichoke. The total length was 151,431 bp, including four conserved regions: A pair of reverse repeat regions (IRa 24,568 bp and IRb 24,603 bp), a large single-copy region (LSC, 83,981 bp), and a small single-copy region (SSC, 18,279 bp). The genome had a total of 115 genes, with 19 present in the reverse direction in the IR region. Thirty-six simple sequence repeats (SSRs) were identified in the coding and noncoding regions, most of which were biased towards $A / T$ bases. Thirty-two SSRs were distributed in the non-coding regions. A comparative analysis of the chloroplast genome sequence of the Jerusalem artichoke and other species of the composite family revealed that the chloroplast genome sequences of plants of the composite family were highly conserved. Differences were observed in 24 gene loci in the coding region, with the degree of differentiation of the ycf2 gene being the most obvious. A phylogenetic analysis showed that Helianthus petiolaris subsp. fallax had the closest relationship with Jerusalem artichoke, both members of the Helianthus genus. Selective locus detection of the ycf2 gene in eight species of the composite family was performed to explore adaptive evolution traits of the $y c f 2$ gene in Jerusalem artichoke. The results show that there are significant and extremely significant positive selection sites at the $1239 \mathrm{~N}$ and $1518 \mathrm{R}$ loci, respectively, indicating that the $y c f 2$ gene has been subject to adaptive evolution. Insights from our assessment of the complete chloroplast genome sequences of Jerusalem 
artichoke will aid in the in-depth study of the evolutionary relationship of the composite family and provide significant sequencing information for the genetic improvement of Jerusalem artichoke. 
2 The complete chloroplast genome of the Jerusalem

3 artichoke (Helianthus tuberosus L.) and an adaptive

4 evolutionary analysis of the ycf2 gene

5

6

7

8
Qiwen Zhong ${ }^{1,2,3 \pi}$, Shipeng Yang ${ }^{2,3 \pi}$, Xuemei Sun ${ }^{1,2,3}$, Lihui Wang ${ }^{2,3}$, Yi Li $^{1 *}$

${ }^{1}$ Qinghai Key Laboratory of Qinghai-Tibet Plateau Biological Resources, Northwest Institute of Plateau Biology, Chinese Academy of Sciences, Xining 810000, Qinghai, China

${ }^{2}$ Qinghai Key Laboratory of Vegetable Genetics and Physiology, Agriculture and Forestry Sciences of Qinghai University, Xining 810016, Qinghai, China

${ }^{3}$ The Open Project of State Key Laboratory of Plateau Ecology and Agriculture, Qinghai University, Xining 810016, Qinghai, China

Corresponding Author:

$\mathrm{Yi} \mathrm{Li}^{1}$

Email address: liyi@nwipb.cas.cn 


\section{Abstract}

Jerusalem artichoke (Helianthus tuberosus L.) is widely cultivated in Northwest China, and it has become an emerging economic crop that is rapidly developing. Because of its elevated inulin content and high resistance, it is widely used in functional food, inulin processing, feed, and ecological management. In this study, Illumina sequencing technology was utilized to assemble and annotate the complete chloroplast genome sequences of Jerusalem artichoke. The total length was 151,431 bp, including four conserved regions: A pair of reverse repeat regions (IRa 24,568 bp and IRb 24,603 bp), a large single-copy region (LSC, 83,981 bp), and a small single-copy region (SSC, 18,279 bp). The genome had a total of 115 genes, with 19 present in the reverse direction in the IR region. Thirty-six simple sequence repeats (SSRs) were identified in the coding and noncoding regions, most of which were biased towards A/T bases. Thirty-two SSRs were distributed in the non-coding regions. A comparative analysis of the chloroplast genome sequence of the Jerusalem artichoke and other species of the composite family revealed that the chloroplast genome sequences of plants of the composite family were highly conserved. Differences were observed in 24 gene loci in the coding region, with the degree of differentiation of the $y c f 2$ gene being the most obvious. A phylogenetic analysis showed that Helianthus petiolaris subsp. fallax had the closest relationship with Jerusalem artichoke, both members of the Helianthus genus. Selective locus detection of the $y c f 2$ gene in eight species of the composite family was performed to explore adaptive evolution traits of the $y c f 2$ gene in Jerusalem artichoke. The results show that there are significant and extremely significant positive selection sites at the $1239 \mathrm{~N}$ and 1518R loci, respectively, indicating that the $y c f 2$ gene has been subject to adaptive evolution.

Insights from our assessment of the complete chloroplast genome sequences of Jerusalem artichoke will aid in the in-depth study of the evolutionary relationship of the composite family and provide significant sequencing information for the genetic improvement of Jerusalem artichoke.

\section{Introduction}

Jerusalem artichoke (Helianthus tuberosus L.) is a species of the composite family native to North America, primarily distributed in the temperate zone of $40-55^{\circ} \mathrm{C}$ north latitude and the temperate region with the approximate similar latitude in the southern hemisphere. Jerusalem artichoke was introduced to China via Europe in the 17th century. It has been grown on a small scale as a pickled vegetable in various regions of China. Jerusalem artichoke is highly resistant and can be grown in saline, alkaline, dry and low temperature conditions. Therefore, it is widely cultivated in various regions of China, especially in the Qinghai plateau in recent years. To date, most research on Jerusalem artichoke has focused on ecological management, feed research and development, and the processing of inulin products. Studies centered on the improvement of saline land in the Songnen Plain have recognized Jerusalem artichoke as an excellent improved crop, which has already been initially grown in saline-alkali grassland (Yan et al. 2008). The aboveground part of Jerusalem artichoke is tall, making it an easily accessible source of animal feed. Furthermore, its leaves are particularly nutritious compared with other feed ingredients, being 
81 rich in lysine and methionine, and having a dry matter content of protein as high as $20 \%$, of which

82

83

84

85

86

87

88

89

90

91

92

93

94

95

96

97

98

99

100

101

102

103

104

105

106

107

108

109

110

111

112

113

114

115

116

117

118

119

$5 \%$ to $6 \%$ corresponds to lysine, an essential amino acid (Rawate \& Hill 1985). Jerusalem artichoke also utilizes fructan as a source of carbon, instead of starch, as most crops. Fructan can be processed or modified, providing the raw materials for the production of bioethanol, paper, and healthcare products (Saengkanuk et al. 2011; Wang et al. 2015; Wyse et al. 2017).

The composite family is the largest group of dicotyledonous chrysanthemums, encompassing 25,000-30,000 species distributed throughout the world. Fifty-two species and a large number of subspecies have been recognized in the Helianthus genus, including Jerusalem artichoke. The morphology of these plants is complex and diverse, leading to difficulties in identification and evolutionary analysis. Jerusalem artichoke is a hexaploid species $(2 \mathrm{n}=6 \mathrm{x}=102)$, which reproduces primarily through vegetative propagation by tubers (Baldini et al. 2004). The evolutionary assessment of this plant is controversial, with its ancestral species remaining uncertain. Hybridization experiments between Jerusalem artichoke and Helianthus annuus L. have confirmed homologous genes between these species. It is generally believed that the chromosome number of triploid hybrid (AAB) in Jerusalem artichoke has doubled. Moreover, cytogenetic studies have demonstrated that two of the three genomes of Jerusalem artichoke are homologous (Atlagić et al. 1993; Kostoff 1934; Kostoff 1939). The diploid $(2 \mathrm{n}=2 \mathrm{x}=34)$ B genome is provided by the immediate ancestor of $H$. annuus $L$., while the autotetraploid $(2 \mathrm{n}=4 \mathrm{x}=68)$ A genome is provided by the crop in the composite family (Bock et al. 2014; Heiser \& Smith 1964; Heiser et al. 1969). Helianthus hirsutusis is regarded as the most likely tetraploid ancestor (Bock et al. 2014), while Helianthus grosseserratus, and Helianthus giganteus are viewed as the most likely diploid ancestors. The sequencing of related species using partial mitochondrial genomes, as well as $35 \mathrm{~S}$ and $5 \mathrm{~S}$ ribosomal DNA, has shown the origin of Jerusalem artichoke to be very rich and probably linked to the hybridization of tetraploid Hairy H. annuus L. and diploid Sawtooth H. annuus L. (Bock et al. 2014; Timme et al. 2007). With the development of high-throughput sequencing technology, chloroplast phylogenetic genome evaluation has become a hot topic in the evolutionary research of plants in recent years. Plenty of phylogenetic information is contained in the chloroplast genome, providing a broad data platform for the study of phyletic evolution, and thereby verifying and extending the results of previous studies. The chloroplast genome sequencing of eight Helianthus species has been completed. However, this aspect remains unexplored concerning Jerusalem artichoke.

Thus, in this study, we report the complete chloroplast genome sequencing, assembly and comparative analysis of Jerusalem artichoke. This data will help elucidate the evolutionary history of Jerusalem artichoke and its phylogenetic position in the composite family. In addition, it will lay a foundation for further studies of population genetics and other molecular aspects of Jerusalem artichoke based on chloroplast DNA sequencing.

\section{Materials \& Methods}

\section{Samples and genome sequencing}

Peer) reviewing PDF | (2019:01:34662:3:1:NEW 25 Jul 2019) 
Fresh tender leaves of Jerusalem artichoke were obtained from the experimental base of the Qinghai Academy of Agricultural and Forestry Sciences (N36 $43^{\prime} 51_{2 .}$ E101 $\left.{ }^{\circ} 45^{\prime} 24\right)$. Chloroplast DNA was extracted through an improved high-throughput chloroplast genome extraction method (Shi et al. 2012). Illumina HiSeq PE150 paired-end sequencing technology was used to establish the library for sequencing. The library was of the DNA small fragment type with $400 \mathrm{bp}, 150 \mathrm{bp}$ read length with the average depth was $100 \times$.

\section{Chloroplast genome assembly and annotation}

FastQC was used for the quality filtering of clean data. SOAPdenovo software was used for pre-assembly (Lee \& Lee 1995), while SPAdes v3.6.2 (http://bioinf.spbau.ru/spades) was used for sequence assembly (Bankevich et al. 2012). The sequence of the chloroplast genome of $H$. annuus $L$. was used as a reference to determine the location of the chloroplast genome. Gapcloser (Luo et al. 2012) and GapFiller (Boetzer \& Pirovano 2012) software for repairing gaps, and PrInSeS-G was then used for sequence correction. DOGMA software (http://dogma.ccbb.utexas.edu/) (Wyman et al. 2004) was used for annotation. The above program uses default parameters. The gene region and protein coding sequence were manually adjusted according to the initiation codon and termination codon sequences. tRNA was entered into tRNAscan-SE (http://lowelab.ucsc.edu/tRNAscan-SE/) for annotation (Lowe \& Chan 2016). rRNA was submitted to the RNAmmer 1.2 Server (http://www.cbs.dtu.dk/services/RNAmmer/) for prediction. The resulting sequence information and annotation results were submitted to Genebank, with the sequence number of MG696658. The Organellar Genome DRAW software (http://ogdraw.mpimp-golm.mpg.de/index.shtml) (Lohse et al. 2013) was used to render a complete circular chloroplast genome map.

\section{Repeats and SSRs analysis}

The chloroplast genome was entered into REPuter (Kurtz et al. 2001)to identify forward and reverse repeat sequences. Simple sequence repeats (SSRs) were identified by MIcroSAtellite (MISA) software based on a perl script (http://pgrc.ipk-gatersleben.de/misa/). The number of repeats from mononucleotide to hexanucleotide was set to 10, 5, 4, 3, 3 and 3 .

\section{Comparative analysis of different Asteraceae plastomes}

The LAGAN model in the mVISTA software (Frazer et al. 2004) was used to perform a comparative analysis of the chloroplast genome of Jerusalem artichoke with Carthamus tinctorius (KX822074.1), Ageratina adenophora (JF826503.1), Guizotia abyssinica (EU549769.1). Lactuca sativa (NC_007578.1), Helianthus argophyllus (KU314500.1), Helianthus debilis (KU312928.1), and Helianthus petiolaris subsp. fallax (KU295560.1). After screening for the quality of the original chloroplast genome data of Jerusalem artichoke, the final constructed sequence (the gene sequence extracted from the annotation) and the established chloroplast genome of 15 plant species were compared by Blast+(ftp://ftp.ncbi.nlm.nih.gov/blast/executables/blast+/LATEST/). HomBlocks (Bi et al. 2018) was used to construct a Circos map (http://circos.ca/) to find the direction, relative position and link color of the genes. This was then standardized according to the length of all the alignment regions. Coloring was performed in accordance with the long, medium, relative short, and short sequence lengths (pink, orange, green, and blue, respectively). COBALT 
160 (https://www.ncbi.nlm.nih.gov/tools/cobalt/cobalt.cgi?CMD=Web) was utilized to compare the

161

162

163

164

165

166

167

168

169

170

171

172

173

174

175

176

177

178

179

180

181

182

183

184

185

186

187

188

189

190

191

192

193

194

195

196

197

198

differential protein sequence $y c f 2$. HomBlocks and COBALT use default parameters.

\section{Phylogenetic analysis}

The following 15 species of the composite family were used for the phylogenetic analysis of Jerusalem artichoke: A. adenophora (JF826503.1), C. tinctorius (KX822074.1), G. abyssinica (NC_010601.1), Jacobaea vulgaris (NC_015543.1), L. sativa (NC_007578.1), H. annuus (NC_007977.1), H. petiolaris subsp. fallax (KU295560.1), H. argophyllus (KU314500.1), H. debilis (KU312928.1), H. annuus cultivar line HA383 (DQ383815.1), H. petiolaris (KU310904.1), H. praecox (KU308401.1), H. annuus subsp. Texanus (KU306406.1), Mikania micrantha (NC_031833.1), and Taraxacum mongolicum (NC_031396.1). MAFFT 7.388 (Katoh et al. 2017) was used to compare 16 chloroplast genome sequences. A phylogenetic tree was constructed with the methods of maximum-likelihood and Bayesian, respectively. The GTRGAMMAI model was used in the ML Tree, and RAxML v8.1.24 (Stamatakis 2014) was used to construct the tree. Parameters were set to search for 30 repeats, and the tree with the maximum likelihood value was used. In addition, Bootstrap was set to run 1000 times to calculate the support of each branch. To build the Bayesian tree, the nucleotide substitution model GTR $+\mathrm{I}+\mathrm{G}$ in Bayesian analysis was selected according to BIC in the jModelTest 2.1.7 software (Darriba et al. 2012). MrBayes 3.2 (Ronquist et al. 2012) was used for calculations, employing the Markov chain Monte Carlo methodology. Four Markov chains were initialized at the same time. The random tree was marked as the initial tree, and one was saved every 500 trees for a total of 5,000,000 trees. The first $20 \%$ of the burn-in trees were discarded. The remaining trees were used to calculate the posterior probability of the consistent tree and each branch.

\section{Adaptive evolution traits}

The ratio $(\omega)$ of the non-synonymous substitution $(\mathrm{dN})$ to the synonymous substitution $(\mathrm{dS})$ of nucleotides is used in most adaptive evolution studies to measure the selection pressure at the nucleic acid or protein level. In addition, the selection pressure is considered to hinder or promote its role in the process of non-synonymous replacement fixation. The positive selection model (M2a, M8) and the control model (M1a, M7, M8a) provided by EasyCodeML software were used to conduct the adaptive evolution analysis in the loci (Gao et al. 2019). The locus model was used to assume that there were different selection pressures at different loci. In other words, the $\omega$ values were different, but there was no difference in the different branches of the phylogenetic tree. This model was primarily used to detect the existence of positive selection $(\omega>1)$ and negative selection $(\omega<1)$ loci in the $y c f 2$ gene. Three pairs of comparison models were Mla (near neutral) and M2a (selection), M0 (single ratio) and M3 (discrete), M7 (beta) and M8 (beta \& $\omega$ ) in this study. The former is a zero hypothesis, and the latter is an alternative hypothesis. Models M0 (single ratio) to M3 (discrete) were used to detect different $\omega$ values at each point rather than detecting positive selection loci. PAMLx V1.3.1 was used to perform the likelihood ratio test (LRT) in three pairs of models (Xu and Yang. 2013). Positive selection loci were tested by comparing the significance of the differences between the models. $\chi^{2}$ distribution was used as the

PeerJ reviewing PDF | (2019:01:34662:3:1:NEW 25 Jul 2019) 
199

200

201

202

203

204

205

206

207

208

209

210

211

212

213

214

215

216

217

218

219

220

221

222

223

224

225

226

227

228

229

230

231

232

233

234

235

236

237

238

significance test under the condition of relative degrees of freedom (the difference between the number of two models).

\section{Results}

\section{Genome organization and gene features}

The chloroplast genome of Jerusalem artichoke had a total length of 151,431 bp. The genome was composed of four parts: A pair of reverse repeat regions, IRa (24,568 bp) and IRb (24,603 bp), separated by a large single-copy region LSC (83981bp) and a small single-copy region SSC (18,279 bp) (Fig. 1). Genes in the coding regions accounted for $55.45 \%$ of the genome, including protein-coding genes, tRNA genes and rRNA genes. The chloroplast genome of Jerusalem artichoke had a total guanine-cytosine content (GC content) of 37.6\%, with GC in the IR region corresponding to $43.2 \%$, and GC in the LSC and SSC regions being $35.6 \%$ and $31.3 \%$, respectively. The chloroplast genome of Jerusalem artichoke contained 115 genes, including 84 protein-coding genes CDS, 27 tRNA genes and four rRNA genes distributed in the IR region. Furthermore, this region encompassed 19 inverse genes, including eight CDS genes ( $y c f 2, n d h B$, $r p s 7, r p s 12, y c f 15, y c f 1, r p l 2$, and $r p l 23$ ), seven tRNA genes, and four rRNA genes. The 115 genes contained 60 Protein synthesis and DNA replication genes, 44 Photosynthesis genes, six Miscellaneous group genes and five pseudogenes of unknown function (Table 1). In the chloroplast genome of Jerusalem artichoke, 16 intron-containing genes were annotated, 11 of which were protein-encoding and five were tRNA genes. Of the 16 intron genes, the intron sequence in $\operatorname{trnK}-U U U$ was the longest $(2,528 \mathrm{bp})$, while the intron in the trnL-UAA gene was the smallest (436 bp). There were two introns in the $c l p P, y c f 3$ and rps 12 genes, whereas the other genes contained only one intron (Table 2). Since Bock et al. have sequenced the Jerusalem artichoke plastid genome, based on this, we performed a detailed comparison (NCBI Accession: NC_023112), and the sequencing results in this study (NCBI Accession: MG696658), which are shown by the results of BRIG (Fig 2). The result of this sequencing indicate that there are $384 \mathrm{bp}$ more than in NC023112, and there are partial base differences in 15 genes: $\operatorname{css} A$, atp $B, \operatorname{clp} P, n d h B$, $n d h H, n d h I$, petA, petD, $r p l 2, r p o C 1, r p o C 2, r p s 12, r p s 16, y c f 1$ and $y c f 2$, with multiple differences in $c l p P$ and $r p o C l$ (Table 3).

\section{Repeats and SSRs analysis}

The distribution of cpSSR in Jerusalem artichoke was analyzed, revealing 36 different SSR loci in its chloroplast genome. Among them, 32 SSR were composed of A or T, two were composed of $\mathrm{C}$, and only one was composed of $\mathrm{G}$, indicating that the chloroplast genomic SSR of Jerusalem artichoke are biased towards A/T bases (Fig 3). An assessment of the SSR distribution identified 32 SSR in the non-coding region of the chloroplast genome. The non-coding region primarily includes an intergenic spacer (IGS) and introns, accounting for $68 \%$ and $20 \%$ of the 
239

240

241

242

243

244

245

246

247

248

249

250

251

252

253

254

255

256

257

258

259

260

261

262

263

264

265

266

267

268

269

270

271

272

273

274

275

276

277

278

distribution, respectively. In the coding region, SSR are only found in the $\operatorname{rpoC2}$, cemA, and $y c f 1$ genes.

\section{Comparative analysis of different composite chloroplast}

A comparative analysis with the plastomes of other species of the composite family revealed only small differences in plastome size and composition in comparison to that of Jerusalem artichoke (Table 4). There were very few inconsistencies in the types and number of chloroplast genes in several species of the composite family, and the types and number were very conserved. The total size chloroplast genome of Jerusalem artichoke ranked 5 th in the aligned genomes of the eight chloroplast genomes of the composite family. The variation in the length of the sequence may be caused by the difference in length between the LSC and IR regions. The chloroplast genome size of eight crops of the composite family was approximately $150 \mathrm{~kb}$, with a GC content of approximately $37.5 \%$. The number of protein-coding genes ranged between 79 and 89 . All of these genomes had four rRNA-coding genes and 20-30 tRNA-coding genes. The plastome of Jerusalem artichoke was 327 bp longer than that of $H$. petiolaris subsp. fallax (a crop in the same genus), primarily in the LSC region. In addition, it had five more protein-coding genes than that of $H$. petiolaris subsp. fallax, with no difference in the number of rRNA- and tRNA-coding genes.

The genomic sequences of eight composite species were analyzed by the mVISTA software, detecting the variations of the sequences (Fig. 4). The results showed there was less variation between Jerusalem artichoke, $H$. petiolaris subsp. fallax and $H$. debilis and $H$. argophyllus. Compared with $A$. adenophora, a partial structure was lacking in the Jerusalem artichoke.

Based on the results of mVISTA, a systematic comparative analysis was performed in a coding region with small variation amplitude (Doorduin et al. 2011). As shown in Fig 5, there were differences among eight species of the composite family in the following 24 gene loci: trnN-GUU, $\operatorname{trnR}-A C G, \operatorname{trn} A-U G U, y c f 68, \operatorname{trnL}-G A U, \operatorname{trn} V-G A C, y c f 15, \operatorname{rps} 7, n d h B, \operatorname{trnL}-C A A, y c f 2, \operatorname{trnL}-$ $C A U, r p l 23, r p l 2, r p s 19, r p s 12, r p l 20, r p s 18, r p l 33, \operatorname{trn} P-U G G, \operatorname{pet} L, \operatorname{trn} G-U C C, \operatorname{trn} S-G C U$, and $\operatorname{trn} C-G C A$. The discovery of these differential genes provides valuable phylogenetic information for the further evaluation of the composite family.

In many studies, the $y c f 2$ gene has become an alternative choice for the assessment of plant sequence variation and phylogenetic evolution. Our results showed that the $y c f 2$ gene segment had a large deletion and inconsistency. The $y c f 2$ gene of Jerusalem artichoke and seven other composite species was compared. Four species of the genus Helianthus had 152 amino acid sequence deletions of the $y c f 2$ gene in the segment 308-460 (Fig 6). In addition, only H.s petiolaris had 12 amino acid sequence deletions in the segment 1524-1536 among four Helianthus species. There were 12 amino acid sequence deletions in segment 1641-1653 of A. adenophora and Lactuca sativa, as well as in the segment 1641-1664 of G. abyssinica. In addition, there were some amino acid site differences. Lastly, the greatest similarity was observed between the $y c f 2$ genes of Jerusalem artichoke and $H$. petiolaris subsp. fallax, with the exception of the presence of five additional amino acids in the start of $y c f 2$ in the Jerusalem artichoke plastome.

PeerJ reviewing PDF | (2019:01:34662:3:1:NEW 25 Jul 2019) 


\section{3}

314

\section{Phylogenetic analysis}

To assess the phylogenetic relationships of Jerusalem artichoke, the chloroplast genomes of 15 species of the composite family were compared globally. J. vulgaris was used as an outgroup, and then RAxML and Bayesian evolutionary trees were constructed, respectively. The resulting phylogenetic trees constructed by the two methods shared the same topological structure (Fig 7). All the species in the composite family formed three highly supported evolutionary clades: members of the genus Helianthus are included in the first clade, including some H. annuus $L$. species, subspecies and Jerusalem artichoke, as well as Eupatorieae and Millerieae. On the evolutionary subclade of the genus Helianthus, Jerusalem artichoke and H. petiolaris subps. fanax are in the closest relationship. The common node bootstrap is fully resolved. L. sativa and $T$. offcinale of the Crepidinae are contained in the second clade, while $J$. vulgaris is clustered alone in the Senecioninae.

\section{Estimation of the positive selection loci of the $y c f 2$ gene in eight species of the composite family}

EasyCodeML v1.2 and paml X1.3 were used to calculate the logarithmic likelihood value ( $\mathrm{InL}$ ) and parameter evaluation for the complete sequence data set of the $y c f 2$ coding region of eight species in the composite family. In the locus model, $\omega>1$ was allowed in the models M3 (discrete), M2a (selection) and M8 (beta \& $\omega$ ) to assume that the corresponding zero hypothetical models were the M1a (near neutral) model, M0 (one-ratio) model and M7 (beta) model. The M3, M2a and M8 models were significantly superior to their corresponding hypothetical models M0, M1a, M7 and M8a $(\mathrm{P}<0.01)$, indicating that there were differences in the selection pressure among the points. After LRT testing, it was found that both M7 vs. M8 and M8a vs. M8 were more consistent with the analyzed data than their original hypothetical models (Table 5), and their original hypothetical models were rejected at a significant level of $\mathrm{P}=0.01$. A consistent positive selection locus, $1239 \mathrm{~N}$ and 1518R, was found in models M2a and M8, respectively, at 95\% and 99\% levels calculated by Naïve Empirical Bayes (NEB) (Table 6). There was one positive selection locus $1518 \mathrm{R}$ in the M2a model and two positive selection loci $1239 \mathrm{~N}$ and $1518 \mathrm{R}$ in the M8 model according to a Bayes Empirical Bayes analysis. Overall, the posterior probabilities of $1239 \mathrm{~N}$ and $1518 \mathrm{R}$ in the NEB analysis of the M2a and M8 models were greater than 95\% and $99 \%$, respectively. Currently, this type of gene has substantial potential for application and diverse functions in the field of plant phylogeny according to the research progress of the chloroplast ycf gene family.

\section{Discussion}

The GC content of the Jerusalem artichoke IR region is high. This may be due to the fact that the IR region contained four high-GC rRNA genes (Asaf et al. 2016). The high G-C content made conservation in the IR regions higher than that in the large single-copy (LSC) and small singlecopy (SSC) regions (Yang et al. 2014). The sequence and composition of the chloroplast genes of 
319 the Jerusalem artichoke were similar to those of other crops of the composite family (Curci et al.

320

321

322

323

324

325

326

327

328

329

330

331

332

333

334

335

336

337

338

339

340

341

342

343

344

345

346

347

348

349

350

351

352

353

354

355

356

357

358

2015). In addition, we compared the plastid genome and the chloroplast genome of the Jerusalem artichoke. This comparison revealed that the plastid genome was $384 \mathrm{bp}$ smaller than the chloroplast genome. We further refined the chloroplast genome of the Jerusalem artichoke via comparison with that produced by Bock et al. Fifteen differentially encoded genes were found in the published Jerusalem artichoke genome sequence (Bock et al. 2014). These differences may be due to the differences in sequencing depth and read length between these studies, as accuracy and length of sequences from the Illumina HiSeq 2000 is less than that from the Illumina HiSeq 2500 PE150, which has $100 \times$ depth. The $95 \times$ is more refined than the genome of the plastid genome, and depth of sequencing affects the number of detected genes, as well as the statistics and expression-related downstream analyses (Desai et al. 2013). A paired-end sequencing approach can also lead to differences in gene detection, as for the same number of reads, paired-end $2 \times 150$ bp reads contain more information than do paired-end $2 \times 100 \mathrm{bp}$ reads(Chaisson et al. 2009). In addition, we employed different genome assembly methods than did Bock et al., which may also result in differences in genome sequencing. In conclusion, a $384 \mathrm{bp}$ difference in the conserved chloroplast genome may be an artifact as a consequence of the results of late cluster analysis studies, as we found that the overall difference in the chloroplasts of the Composite family ranged between 200 and $400 \mathrm{bp}$. These results will aid future chloroplast genome evolution studies and research on the positive selection of genes. Based on these sequencing results, we were able to comprehensively analyze the characteristics of the Jerusalem artichoke chloroplast genome.

Introns play an important role in selective gene splicing. Because the chloroplast genome was simple, relatively conserved and maternal, chloroplast SSR were highly efficient molecular markers. Moreover, chloroplast simple sequence repeats (cpSSRs) have been widely used previously in crossbreeding, biogeography, and population genetics studies (Bayly et al. 2013). This is consistent with the chloroplast genomes of most angiosperms (Raveendar et al. 2015; Yang et al. 2014). In regards to repeat length, most SSR had 10-20 bp, while fewer had less than $10 \mathrm{bp}$, indicating that the SSR segment of the Jerusalem artichoke chloroplast genome is short. However, the long repeated sequence might promote the rearrangement of the chloroplast genome, causing an increase in population genetic diversity (Qian et al. 2013). This may be related to the vegetative propagation of Jerusalem artichoke, which greatly reduces the probability of genetic variation. The SSR sites distributed in the non-coding region are the majority, while only three genes in the coding region have SSR sites, and there are few SSR sites in the coding region of the chloroplast genome, as has been confirmed in Quercus and Saxifragaceae (Liu et al. 2018; Yang et al. 2016). These repetitive structures provide valuable information resources for the future development of molecular markers in the study of the phylogenetic evolution and population genetics of Jerusalem artichoke.

A comparative analysis of the coding regions in the chloroplast genome of plants in the composite family showed that Jerusalem artichoke and H. petiolaris subsp. fallax had the fewest differences.

PeerJ reviewing PDF | (2019:01:34662:3:1:NEW 25 Jul 2019) 
359

360

361

362

363

364

365

366

367

368

369

370

371

372

373

374

375

376

377

378

379

380

381

382

383

384

385

386

387

388

389

390

391

392

393

394

395

396

397

398

As a whole, the chloroplast genome of crops in the composite family tends to be conserved. An mVISTA analysis showed that the coding region was more conserved than the non-coding region, which is consistent with reports on crops in the composite family, such as Cynara cardunculus (Curci et al. 2015) and A. adenophora (Nie et al. 2012). The $y c f 2$ gene showed the greatest degree of differentiation. In addition, there was a gene deletion in the crops of genus Helianthus. Currently, many different gene regions are considered potential tools for phylogenetic analysis. These DNA domains will play an important role in the application of molecular phylogeny in this species (Nie et al. 2012). The $y c f 2$ gene is the largest known plastid gene in angiosperms (Drescher et al. 2000b). Although the $y c f 2$ gene can be used to predict phylogenetic relationships (Drescher et al. 2000a), its function remains unclear. This suggests that the $y c f 2$ gene is highly conserved in the evolution of the species within the composite family. The $y c f 2$ gene appears to gradually degenerate compared in gramineous crops, with only $734 \mathrm{bp}$ remaining in rice and wheat (Matsuoka et al. 2003). The results of phylogenetic tree analysis using partial angiosperm $y c f 2$ genes were consistent with those obtained from the whole plastid genome data phylogenetic tree analysis. This provides even more precise details for evolutionary evaluation (Doorduin et al. 2011).

The composite family is one of the largest families in the plant kingdom, and the chloroplast genome plays an important role in plant classification and phylogenetic analysis. To date, abundant research has evaluated the phylogeny of crops in the composite family. Notably, study of the evolution of the Aster spathulifolius chloroplast genome has revealed that it bears its closest relationship with $J$. vulgaris (Choi \& Park 2015; HUANG et al. 2010; SOLTIS et al. 2000), which is consistent with previous reports on the uncertainty of the evolution of the Senecioninae tribe (Doorduin et al. 2011). In the group of the composite in which the number of involved species is more than or equal to 2, it can be seen that genetically Jerusalem artichoke is more closely related to other species of composite family, such as genus Helianthus. At the same time, Jerusalem artichoke is also the earliest isolated species of the genus Helianthus. This provides a theoretical basis for the further study of the relationship between phylogenetic branches of Jerusalem artichoke in the composite family.

The $y c f 2$ gene fragment is large, and the function of its open reading frame (ORF) fragment is not clear. Compared with other chloroplast coding genes, the nucleotide sequence identity between $y c f 2$ of different families is very low, which is less than $50 \%$ in bryophytes, pteridophytes and spermatophytes (Wicke et al. 2011). In the increasing number of $y c f$ gene studies, although $y c f 2$ is highly conserved, the $y c f 2$ gene shows a wealth of phylogenetic information in the Orchidaceae phylogeny. Huang et al. found that the $y c f 2$ gene has multiple positive selection loci during angiosperm development, and the phylogenetic signal of $y c f 2$ probably originates from its large sequence length, so that the $y c f 2$ gene is valuable for future research (Huang et al. 2010). Most chloroplast genes were in a negative selection state in Holcoglossum, but 14 positive selection loci were detected in the $y c f 2$ gene (Li et al. 2019). In this study, some positive selection signals were

Peer) reviewing PDF | (2019:01:34662:3:1:NEW 25 Jul 2019) 
399

400

401

402

403

404

405

406

407

408

409

410

411

412

413

414

415

416

417

418

419

420

421

422

423

424

425

426

427

428

429

430

431

432

433

434

435

436

437

438

439

found by establishing evolutionary trees of the adaptive evolution of the $y c f 2$ gene in the composite family, but the loci were few, which may be related to the number of species. Plants may have a variety of strategies to adapt to the environment, and adaptive modifications to other abiotic stresses of genes in the nucleus are sufficient to maintain the homeostasis of photosynthesis. Therefore, there is no need for adaptive evolution in the chloroplast coding genes (Dolhi et al. 2013; Hirooka et al. 2017; Wang et al. 2019). In this study, research on the $y c f 2$ gene in the composite family supports the idea of adaptive evolution, but there are currently few studies on adaptive evolution in Compositae crops. Therefore, further studies on the adaptive evolution of chloroplast genes in other species of the composite family are needed to explore how to adapt to these changes in environmental migration and climate change.

\section{Conclusions}

In this study, the complete chloroplast genome sequence of Jerusalem artichoke was successfully assembled, annotated and analyzed. The chloroplast genome of the plants in the composite family is relatively conserved. Variations of the chloroplast genome are scarce between Jerusalem artichoke and plants in the same genus. Compared with composite plants belonging to other genera, we found deletions in the chloroplast genome of Jerusalem artichoke. The identification of repetitive sequences in the chloroplast genome of Jerusalem artichoke, particularly SSR, will be helpful for the development of molecular markers, the study of population genetics and the phylogenetic analysis of Jerusalem artichoke. A phylogenetic analysis of plants in the composite family shows that Jerusalem artichoke and Helianthus petiolaris subsp. fallax share the closest relationship, both belonging to the composite family, genus Helianthus. The results of this study indicate $y c f 2$ gene has been subject to adaptive evolution, and it is suggested that more extensive investigation and in-depth discussion should be conducted in future studies. Completion of the sequencing of the chloroplast genome will provide key genetic information for further research on Jerusalem artichoke and deepen our understanding on the evolutionary history of the chloroplast genome and phylogenetic position of Jerusalem artichoke. In addition, it may be useful for various molecular biology applications of Jerusalem artichoke in the future.

\section{References}

Asaf S, Khan AL, Khan AR, Waqas M, Kang S-M, Khan MA, Lee S-M, and Lee I-J. 2016. Complete Chloroplast Genome of Nicotiana otophora and its Comparison with Related Species. Front Plant Sci 7. 10.3389/fpls.2016.00843

Atlagić J, Dozet B, and ŠKorić D. 1993. Meiosis and Pollen Viability in Helianthus tuberosus L. and its Hybrids with Cultivated Sunflower. Plant Breeding 111:318-324. doi:10.1111/j.1439-0523.1993.tb00648.x

Baldini M, Danuso F, Turi M, and Vannozzi GP. 2004. Evaluation of new clones of Jerusalem artichoke (Helianthus tuberosus L.) for inulin and sugar yield from stalks and tubers. Industrial Crops and Products 19:25-40. https://doi.org/10.1016/S0926-6690(03)00078-5 
440

441

442

443

444

445

446

447

448

449

450

451

452

453

454

455

456

457

458

459

460

461

462

463

464

465

466

467

468

469

470

471

472

473

474

475

476

477

478

479

480

481

482

483

484

485

486

487

488

489

Bankevich A, Nurk S, Antipov D, Gurevich AA, Dvorkin M, Kulikov AS, Lesin VM, Nikolenko SI, Pham S, Prjibelski AD, Pyshkin AV, Sirotkin AV, Vyahhi N, Tesler G, Alekseyev MA, and Pevzner PA. 2012. SPAdes: A New Genome Assembly Algorithm and Its Applications to Single-Cell Sequencing. Journal of Computational Biology 19:455-477. 10.1089/cmb.2012.0021

Bayly MJ, Rigault P, Spokevicius A, Ladiges PY, Ades PK, Anderson C, Bossinger G, Merchant A, Udovicic F, Woodrow IE, and Tibbits J. 2013. Chloroplast genome analysis of Australian eucalypts - Eucalyptus, Corymbia, Angophora, Allosyncarpia and Stockwellia (Myrtaceae). Molecular Phylogenetics and Evolution 69:704-716. https://doi.org/10.1016/j.ympev.2013.07.006

Bi G, Mao Y, Xing Q, and Cao M. 2018. HomBlocks: A multiple-alignment construction pipeline for organelle phylogenomics based on locally collinear block searching. Genomics 110:1822. https://doi.org/10.1016/j.ygeno.2017.08.001

Bock DG, Kane NC, Ebert DP, and Rieseberg LH. 2014. Genome skimming reveals the origin of the Jerusalem Artichoke tuber crop species: neither from Jerusalem nor an artichoke. New Phytologist 201:1021-1030.

Boetzer M, and Pirovano W. 2012. Toward almost closed genomes with GapFiller. Genome Biology 13:R56. 10.1186/gb-2012-13-6-r56

Chaisson MJ, Brinza D, and Pevzner PA. 2009. De novo fragment assembly with short matepaired reads: Does the read length matter? Genome Research 19:336-346.

Choi KS, and Park S. 2015. The complete chloroplast genome sequence of Aster spathulifolius (Asteraceae); genomic features and relationship with Asteraceae. Gene 572:214-221. https://doi.org/10.1016/j.gene.2015.07.020

Curci PL, De Paola D, Danzi D, Vendramin GG, and Sonnante G. 2015. Complete Chloroplast Genome of the Multifunctional Crop Globe Artichoke and Comparison with Other Asteraceae. PLoS One 10:e0120589. 10.1371/journal.pone.0120589

Darriba D, Taboada GL, Doallo R, and Posada D. 2012. jModelTest 2: more models, new heuristics and parallel computing. Nature Methods 9:772. 10.1038/nmeth.2109

https://www.nature.com/articles/nmeth.2109\#supplementary-information

Desai A, Marwah VS, Yadav A, Jha V, Dhaygude K, Bangar U, Kulkarni V, and Jere A. 2013. Identification of optimum sequencing depth especially for de novo genome assembly of small genomes using next generation sequencing data. PLoS One 8:e60204.

Doorduin L, Gravendeel B, Lammers Y, Ariyurek Y, Chin-A-Woeng T, and Vrieling K. 2011. The Complete Chloroplast Genome of 17 Individuals of Pest Species Jacobaea vulgaris: SNPs, Microsatellites and Barcoding Markers for Population and Phylogenetic Studies. DNA Research 18:93-105. 10.1093/dnares/dsr002

Drescher A, Ruf S, Calsa T, Carrer H, and Bock R. 2000a. The two largest chloroplast genomeencoded open reading frames of higher plants are essential genes. The Plant Journal 22:97-104. doi:10.1046/j.1365-313x.2000.00722.x

Drescher A, Ruf S, Calsa T, Carrer H, and Bock R. 2000b. The two largest chloroplast genome - encoded open reading frames of higher plants are essential genes. The Plant Journal 22:97-104. doi:10.1046/j.1365-313x.2000.00722.x

Frazer KA, Lior P, Alexander P, Rubin EM, and Inna D. 2004. VISTA: computational tools for comparative genomics. Nucleic Acids Research 32:W273.

Gao F, Chen C, Arab DA, Du Z, He Y, Ho SYW. 2019. EasyCodeML: A visual tool for analysis of selection using CodeML. Ecol Evol. 9: 3891-3898. https://doi.org/10.1002/ece3.5015

Garcia PM, Hayashi AH, Silva EA, Figueiredo-Ribeiro Rde C, and Carvalho MA. 2015. Structural and metabolic changes in rhizophores of the Cerrado species Chrysolaena obovata (Less.) Dematt. as influenced by drought and re-watering. Front Plant Sci 6:721. 10.3389/fpls.2015.00721

Peer) reviewing PDF | (2019:01:34662:3:1:NEW 25 Jul 2019) 
490

491

492

493

494

495

496

497

498

499

500

501

502

503

504

505

506

507

508

509

510

511

512

513

514

515

516

517

518

519

520

521

522

523

524

525

526

527

528

529

530

531

532

533

534

535

536

537

538

539

540

Guo H, Liu J, Luo L, Wei X, Zhang J, Qi Y, Zhang B, Liu H, and Xiao P. 2017. Complete chloroplast genome sequences of Schisandra chinensis: genome structure, comparative analysis, and phylogenetic relationship of basal angiosperms. Science China Life Sciences 60:1286-1290. 10.1007/s11427-017-9098-5

Heiser CB, and Smith DM. 1964. SPECIES CROSSES IN HELIANTHUS: II. POLYPLOID SPECIES. Rhodora 66:344-358.

Heiser CB, Smith DM, Clevenger SB, and Martin WC. 1969. THE NORTH AMERICAN SUNFLOWERS (HELIANTHUS). Memoirs of the Torrey Botanical Club 22:1-218.

HUANG J-L, SUN G-L, and ZHANG D-M. 2010. Molecular evolution and phylogeny of the angiosperm ycf2 gene. Journal of Systematics and Evolution 48:240-248. doi:10.1111/j.1759-6831.2010.00080.x

Katoh K, Rozewicki J, and Yamada KD. 2017. MAFFT online service: multiple sequence alignment, interactive sequence choice and visualization. Briefings in Bioinformatics:bbx108-bbx108. 10.1093/bib/bbx108

Kostoff D. 1934. A Haploid Plant of Nicotiana sylvestris. Nature 133:949. 10.1038/133949b0

Kostoff D. 1939. Autosyndesis and structural hybridity in F1-hybrid Helianthus tuberosus L. $\mathrm{x}$ Helianthus annuus L. and their sequences. Genetica 21:285-300. 10.1007/bf01508121

Kurtz S, ., Choudhuri JV, Ohlebusch E, ., Schleiermacher C, ., Stoye J, ., and Giegerich R, . 2001. REPuter: the manifold applications of repeat analysis on a genomic scale. Nucleic Acids Research 29:4633-4642.

Lee WI, and Lee G. 1995. From natural language to shell script: A case-based reasoning system for automatic UNIX programming. Expert Systems with Applications 9:71-79. https://doi.org/10.1016/0957-4174(94)00050-6

Liu L, Wang Y, He P, Li P, Lee J, Soltis DE, and Fu C. 2018. Chloroplast genome analyses and genomic resource development for epilithic sister genera Oresitrophe and Mukdenia (Saxifragaceae), using genome skimming data. BMC genomics 19:235.

Lohse M, Drechsel O, Kahlau S, and Bock R. 2013. OrganellarGenomeDRAW—a suite of tools for generating physical maps of plastid and mitochondrial genomes and visualizing expression data sets. Nucleic acids research 41:W575-W581.

Lowe TM, and Chan PP. 2016. tRNAscan-SE On-line: integrating search and context for analysis of transfer RNA genes. Nucleic Acids Research 44:W54-W57. 10.1093/nar/gkw413

Luo R, Liu B, Xie Y, Li Z, Huang W, Yuan J, He G, Chen Y, Pan Q, Liu Y, Tang J, Wu G, Zhang $H$, Shi Y, Liu Y, Yu C, Wang B, Lu Y, Han C, Cheung DW, Yiu S-M, Peng S, Xiaoqian Z, Liu G, Liao X, Li Y, Yang H, Wang J, Lam T-W, and Wang J. 2012. SOAPdenovo2: an empirically improved memory-efficient short-read de novo assembler. GigaScience 1:18. 10.1186/2047-217x-1-18

Matsuoka Y, Yamazaki Y, Ogihara Y, and Tsunewaki K. 2003. Whole Chloroplast Genome Comparison of Rice, Maize, and Wheat: Implications for Chloroplast Gene Diversification and Phylogeny of Cereals.

Nie X, Lv S, Zhang Y, Du X, Wang L, Biradar SS, Tan X, Wan F, and Weining S. 2012. Complete Chloroplast Genome Sequence of a Major Invasive Species, Crofton Weed (Ageratina adenophora). PLoS One 7:e36869. 10.1371/journal.pone.0036869

Qian J, Song J, Gao H, Zhu Y, Xu J, Pang X, Yao H, Sun C, Li Xe, Li C, Liu J, Xu H, and Chen S. 2013. The Complete Chloroplast Genome Sequence of the Medicinal Plant Salvia miltiorrhiza. PLoS One 8:e57607. 10.1371/journal.pone.0057607

Raveendar S, Na Y-W, Lee J-R, Shim D, Ma K-H, Lee S-Y, and Chung J-W. 2015. The Complete Chloroplast Genome of Capsicum annuum var. glabriusculum Using Illumina Sequencing. Molecules 20:13080.

Rawate PD, and Hill RM. 1985. Extraction of a high-protein isolate from Jerusalem artichoke (Helianthus tuberosus) tops and evaluation of its nutrition potential. Journal of Agricultural and Food Chemistry 33:29-31. 10.1021/jf00061a008

Peer) reviewing PDF | (2019:01:34662:3:1:NEW 25 Jul 2019) 
541

542

543

544

545

546

547

548

549

550

551

552

553

554

555

556

557

558

559

560

561

562

563

564

565

566

567

568

569

570

571

572

573

574

575

576

577

578

579

580

581

582

Ronquist F, Teslenko M, van der Mark P, Ayres DL, Darling A, Höhna S, Larget B, Liu L, Suchard MA, and Huelsenbeck JP. 2012. MrBayes 3.2: Efficient Bayesian Phylogenetic Inference and Model Choice Across a Large Model Space. Systematic Biology 61:539-542. $10.1093 /$ sysbio/sys029

Saengkanuk A, Nuchadomrong S, Jogloy S, Patanothai A, and Srijaranai S. 2011. A simplified spectrophotometric method for the determination of inulin in Jerusalem artichoke (Helianthus tuberosus L.) tubers. European Food Research and Technology 233:609. $10.1007 / \mathrm{s} 00217-011-1552-3$

Shi C, Hu N, Huang H, Gao J, Zhao Y-J, and Gao L-Z. 2012. An Improved Chloroplast DNA Extraction Procedure for Whole Plastid Genome Sequencing. PLoS One 7:e31468. 10.1371/journal.pone.0031468

SOLTIS DE, SOLTIS PS, CHASE MW, MORT ME, ALBACH DC, ZANIS M, SAVOLAINEN V, HAHN WH, HOOT SB, FAY MF, AXTELL M, SWENSEN SM, PRINCE LM, KRESS WJ, NIXON KC, and FARRIS JS. 2000. Angiosperm phylogeny inferred from 18S rDNA, rbcL, and atpB sequences. Botanical Journal of the Linnean Society 133:381-461. doi:10.1111/j.1095-8339.2000.tb01588.x

Stamatakis A. 2014. RAxML version 8: a tool for phylogenetic analysis and post-analysis of large phylogenies. Bioinformatics 30:1312-1313. 10.1093/bioinformatics/btu033

Timme RE, Simpson BB, and Linder CR. 2007. High-resolution phylogeny for Helianthus (Asteraceae) using the 18S-26S ribosomal DNA external transcribed spacer. American Journal of Botany 94:1837-1852. doi:10.3732/ajb.94.11.1837

Wang Y-Z, Zou S-M, He M-L, and Wang C-H. 2015. Bioethanol production from the dry powder of Jerusalem artichoke tubers by recombinant Saccharomyces cerevisiae in simultaneous saccharification and fermentation. Journal of Industrial Microbiology \& Biotechnology 42:543-551. 10.1007/s10295-014-1572-7

Wyman SK, Jansen RK, and Boore JL. 2004. Automatic annotation of organellar genomes with DOGMA. Bioinformatics 20:3252-3255. 10.1093/bioinformatics/bth352

Wyse DL, Young FL, and Jones RJ. 2017. Influence of Jerusalem Artichoke (Helianthus tuberosus) Density and Duration of Interference on Soybean (Glycine max) Growth and Yield. Weed Science 34:243-247. 10.1017/S0043174500066753

$\mathrm{Xu}, \mathrm{Bo}$, and Ziheng Yang. 2013. "PAMLX: a graphical user interface for PAML." Molecular biology and evolution 30: 2723-2724. 10.1093/molbev/mst179

Yan X, Li Y, and Wang Y. 2008. Jerusalem artichoke, an optimal plant for the improvement of alkalic grassland in Songnen Plain,China. Journal of Natural Science of Heilongjiang University.

Yang Y, Yuanye D, Qing L, Jinjian L, Xiwen L, and Yitao W. 2014. Complete Chloroplast Genome Sequence of Poisonous and Medicinal Plant Datura stramonium: Organizations and Implications for Genetic Engineering. PLoS One 9:e110656. 10.1371/journal.pone.0110656

Yang Y, Zhou T, Duan D, Yang J, Feng L, and Zhao G. 2016. Comparative analysis of the complete chloroplast genomes of five Quercus species. Front Plant Sci 7:959.

Peer) reviewing PDF | (2019:01:34662:3:1:NEW 25 Jul 2019) 


\section{Table 1 (on next page)}

Table 1 List of genes in the chloroplast genome of Helianthus tuberosus L. 
1 Table 1 List of genes in the chloroplast genome of Helianthus tuberosus L.

\begin{tabular}{|c|c|c|}
\hline & Groups of genes & Names of genes \\
\hline Protein & Ribosomal RNAs & $16 S r R N A(2 \times), 23 S r R N A(2 \times), 4.5 S r$ \\
\hline \multirow{15}{*}{$\begin{array}{r}\text { synthesis and } \\
\text { DNA } \\
\text { replication }\end{array}$} & & $R N A(2 \times), 5 \operatorname{Sr} R N A(2 \times)$ \\
\hline & \multirow[t]{8}{*}{ Transfer RNAs } & $\operatorname{trn} Q-T T G, \operatorname{trn} L-T A G, \operatorname{trn} D-G T C, \operatorname{trnS}-$ \\
\hline & & $G G A, \operatorname{trn} E-T T C, \operatorname{trn} S-G C T, \operatorname{trn} Y-G T A$, \\
\hline & & $\operatorname{trn} V-G A C, \operatorname{trn} P-T G G, \operatorname{trn} H-G T G, \operatorname{trnF}-$ \\
\hline & & $G A A, \operatorname{trn} N-G T T, \operatorname{trn} T-T G T, \operatorname{trn} W-C C A$, \\
\hline & & $\operatorname{trn} S-T G A, \operatorname{trn} V-G A C, \operatorname{trn} L-C A A(2 \times)$ \\
\hline & & $\operatorname{trn} M-C A T(2 \times), \operatorname{trn} C-G C A, \operatorname{trnI}-C A T, \operatorname{trn} T-$ \\
\hline & & $G G T, \operatorname{trn} I-C A T, \operatorname{trnR}-A C G, \operatorname{trn} N-G T T$, \\
\hline & & $\operatorname{trn} R-T C T, \operatorname{trn} R-A C G, \operatorname{trn} G-G C C$ \\
\hline & Ribosomal protein & rps $7, r p s 14, r p s 12, r p s 2, r p s 4, r p s 12, r p s 7$ \\
\hline & small subunit & rps11, rps16, rps12, rps19(2×), rps3, \\
\hline & & rps $15, \operatorname{rps} 8, \operatorname{rps} 19$ \\
\hline & Ribosomal protein & rpl14, rpl23, rpl36, rpl2, rpl20, rpl2, rpl32, \\
\hline & large subunit & rpl16, rpl33, rpl23, rpl22 \\
\hline & $\begin{array}{l}\text { Subunit s of RNA } \\
\text { polymerase }\end{array}$ & $r p o B, r p o C(2 \times), r p o A$, \\
\hline \multirow{10}{*}{$\begin{array}{l}\text { Photosynthesi } \\
s\end{array}$} & Photosystem I & psaC, psaA, psaB, psaI, psaJ \\
\hline & Photosystem II & $p s b Z, p s b K, p s b B, p s b I, p s b F, p s b N, p s b L$ \\
\hline & & $p s b J, p s b C, p s b E, p s b M, p s b H, p s b A$, \\
\hline & & $p s b D, p s b T$ \\
\hline & $\begin{array}{l}\text { Cytochrome b/f } \\
\text { complex }\end{array}$ & pet $A, \operatorname{pet} D, \operatorname{pet} L, \operatorname{pet} B, \operatorname{pet} G, \operatorname{pet} N$ \\
\hline & ATP synthase & atpE, atpH, atp $A$, atpI, atpF, atpB \\
\hline & NADH- & $n d h J, n d h A, n d h K(2 \times), n d h G, n d h I$ \\
\hline & dehydrogenase & $n d h B(2 \times), n d h H, n d h E, n d h D, n d h C$, \\
\hline & & $n d h F$ \\
\hline & Large subunit Rubisco & $r b c L$ \\
\hline \multirow{5}{*}{$\begin{array}{l}\text { Miscellaneous } \\
\text { group }\end{array}$} & Translation initiation & $\inf A$ \\
\hline & factor IF-1 & \\
\hline & Acetyl-CoA & $a c c D$ \\
\hline & carboxylase & \\
\hline & Cytochrome c & $\operatorname{ccs} A(2 \times)$ \\
\hline
\end{tabular}




\begin{tabular}{rll} 
& Maturase & matK \\
& ATP-dependent & $c l p P$ \\
protease & \\
& Inner membrane & $c e m A$ \\
& protein & \\
Pseudogenes & Conserved & $y c f 15(4 \times), y c f 4, y c f 3, y c f 1(2 \times), y c f 2(2 \times)$ \\
of unknown & hypothetical & \\
function & chloroplast open & \\
& reading frame & \\
\hline
\end{tabular}

2 


\section{Table 2 (on next page)}

Table 2 Characteristics of genes including introns and exons in the chloroplast genome of Helianthus tuberosus L. 
1 Table 2 Characteristics of genes including introns and exons in the chloroplast genome of

2 Helianthus tuberosus $\mathbf{L}$.

\begin{tabular}{|c|c|c|c|c|c|c|}
\hline Gene & Region & $\begin{array}{l}\text { Exon I } \\
\text { (bp) }\end{array}$ & $\begin{array}{l}\text { Intron I } \\
(\mathrm{bp})\end{array}$ & $\begin{array}{l}\text { Exon II } \\
\text { (bp) }\end{array}$ & $\begin{array}{l}\text { Intron II } \\
\text { (bp) }\end{array}$ & $\begin{array}{l}\text { Exon III } \\
\text { (bp) }\end{array}$ \\
\hline trnK-UUU & LSC & 51 & 2528 & 36 & & \\
\hline $\operatorname{rps} 16$ & LSC & 29 & 864 & 226 & & \\
\hline rpoC1 & LSC & 431 & 733 & 1727 & & \\
\hline $\operatorname{atpF}$ & LSC & 144 & 714 & 391 & & \\
\hline$y c f 3$ & LSC & 152 & 746 & 229 & 700 & 123 \\
\hline$t r n \mathrm{~L}-\mathrm{UAA}$ & LSC & 36 & 436 & 49 & & \\
\hline trnV-UAC & LSC & 36 & 574 & 37 & & \\
\hline$c l p \mathrm{P}$ & LSC & 68 & 792 & 290 & 624 & 227 \\
\hline pet $\mathrm{B}$ & LSC & 5 & 775 & 641 & & \\
\hline petD & LSC & 8 & 712 & 473 & & \\
\hline rpl2 & LSC & 392 & 663 & 434 & & \\
\hline$n d h \mathrm{~B}$ & IR & 755 & 671 & 776 & & \\
\hline trnI-GAU & IR & 41 & 776 & 34 & & \\
\hline $\operatorname{trn} \mathrm{A}-\mathrm{UGC}$ & IR & 37 & 822 & 34 & & \\
\hline ndhA & $\mathrm{SSC}$ & 552 & 1095 & 538 & & \\
\hline rps 12 & LSC-IR & 113 & & 230 & & 29 \\
\hline
\end{tabular}

3 
Table 3 (on next page)

Table 3 Comparison of chloroplast and plastid differential genes in Helianthus tuberosus L. 
1 Table 3 Comparison of chloroplast and plastid differential genes in Helianthus tuberosus $\mathbf{L}$.

\begin{tabular}{|c|c|c|c|c|c|c|}
\hline \multirow[t]{2}{*}{ Gene } & \multirow{2}{*}{$\begin{array}{l}\text { NCBI } \\
\text { Accession }\end{array}$} & \multicolumn{4}{|c|}{ Difference site } & \multirow[t]{2}{*}{ Difference position and base } \\
\hline & & $T$ & $C$ & $A$ & $G$ & \\
\hline \multirow[t]{2}{*}{$\operatorname{ccs} \mathrm{A}$} & MG696658 & 36.8 & 15.6 & 31.6 & 16.0 & \\
\hline & NC023112 & 36.9 & 15.5 & 31.6 & 16.0 & $579 \mathrm{~T}$ \\
\hline \multirow[t]{2}{*}{ atpB } & MG696658 & 36.8 & 15.6 & 31.6 & 16.0 & \\
\hline & $\mathrm{NC} 023112$ & 36.9 & 15.5 & 31.6 & 16.0 & $348 \mathrm{G}$ \\
\hline \multirow[t]{2}{*}{ clpP } & MG696658 & 28.9 & 18.0 & 28.6 & 24.5 & 361-363null \\
\hline & NC023112 & 29.1 & 18.1 & 28.3 & 24.5 & $362 \mathrm{G} / 363 \mathrm{C} / 70,361 \mathrm{~T}$ \\
\hline \multirow[t]{2}{*}{ ndhB } & MG696658 & 34.7 & 19.6 & 27.6 & 18.0 & \\
\hline & $\mathrm{NC} 023112$ & 34.8 & 19.5 & 27.9 & 17.8 & 778-819null \\
\hline \multirow[t]{2}{*}{ ndhH } & MG696658 & 31.0 & 15.2 & 30.9 & 22.9 & \\
\hline & NC023112 & 30.9 & 15.2 & 30.9 & 23.0 & $822 \mathrm{G}$ \\
\hline \multirow[t]{2}{*}{ ndhI } & MG696658 & 34.1 & 16.2 & 31.5 & 18.2 & \\
\hline & NC023112 & 33.9 & 16.4 & 31.5 & 18.2 & $433 \mathrm{C}$ \\
\hline \multirow[t]{2}{*}{ petA } & MG696658 & 28.9 & 19.3 & 30.8 & 21.0 & \\
\hline & NC023112 & 28.9 & 19.3 & 30.7 & 21.1 & $705 \mathrm{G}$ \\
\hline \multirow[t]{2}{*}{ petD } & MG696658 & 32.9 & 19.0 & 27.5 & 20.5 & \\
\hline & NC023112 & 32.9 & 19.0 & 27.7 & 20.3 & $9 \mathrm{~A}$ \\
\hline \multirow[t]{2}{*}{$\mathrm{rpl} 2$} & MG696658 & 22.9 & 18.2 & 33.5 & 25.4 & \\
\hline & NC023112 & 22.9 & 18.3 & 33.5 & 25.3 & 392-394null \\
\hline \multirow[t]{2}{*}{ rpoC1 } & MG696658 & 30.0 & 16.9 & 32.4 & 20.7 & 2-22null \\
\hline & NC023112 & 30.0 & 16.9 & 32.4 & 20.7 & $\begin{array}{l}4,5,8,10,11,22 \mathrm{~A} / 3,6,9,12, \mathrm{G} / 7,17,20, \mathrm{C} \\
/ 2,13,14,15,16,18,19,21 \mathrm{~T} .\end{array}$ \\
\hline
\end{tabular}

$\begin{array}{lllllll}\text { rpoC2 } & \text { MG696658 } & 29.4 & 17.9 & 32.5 & 20.2 & \\ & \text { NC023112 } & 29.4 & 17.9 & 32.6 & 20.2 & \\ \text { rps12 } & \text { MG696658 } & 23.7 & 21.3 & 33.1 & 21.9 & 347 \text { null } \\ & \text { NC023112 } & 24.6 & 21.6 & 30.8 & 23.0 & 346,356 \mathrm{~A} / 347,349,351,354 \mathrm{G}, 352 \mathrm{~T} / \\ & & & & & & 358-376 \text { null }\end{array}$

$\begin{array}{llllll}\text { rps16 } & \text { MG696658 } & 28.5 & 17.2 & 33.0 & 21.3\end{array}$

$\begin{array}{llllll}\mathrm{NC} 023112 & 28.6 & 16.5 & 33.7 & 21.2 & 43-54 \text { null }\end{array}$




$\begin{array}{lllllll}\text { ycf1 } & \text { MG696658 } & 30.6 & 14.2 & 39.6 & 15.6 & \\ & \text { NC023112 } & 30.6 & 14.2 & 39.7 & 15.5 & \begin{array}{l}\text { 1A. } \\ \end{array} \\ & & & & & & 2-4 \text { null } \\ \text { ycf2 } & \text { MG696658 } & 31.1 & 18.5 & 31.2 & 19.2 & \\ & \text { NC023112 } & 31.1 & 18.5 & 31.2 & 19.1 & 4562-4597 \text { null }\end{array}$

2 
Table 4 (on next page)

Table 4 Comparison of $\mathrm{cp}$ genomes among 8 composite species 
1 Table 4 Comparison of cp genomes among 8 composite species

\begin{tabular}{|c|c|c|c|c|c|c|c|c|c|}
\hline \multirow[b]{2}{*}{ Species } & \multicolumn{4}{|c|}{ Size(bp) } & \multirow[b]{2}{*}{$\begin{array}{l}\mathrm{G}+\mathrm{C}( \\
\%)\end{array}$} & \multicolumn{3}{|c|}{$\begin{array}{l}\text { Total number of } \\
\text { genes }\end{array}$} & \multirow[b]{2}{*}{$\begin{array}{l}\text { GeneBa } \\
\text { nk } \\
\text { accessio } \\
\text { ns }\end{array}$} \\
\hline & Total & LSC & IR & $\mathrm{SSC}$ & & $\begin{array}{l}\text { Protei } \\
\mathrm{n}- \\
\text { codin } \\
\mathrm{g} \\
\text { genes }\end{array}$ & $\begin{array}{l}\mathrm{rRN} \\
\mathrm{As}\end{array}$ & $\begin{array}{l}\text { tRN } \\
\text { As }\end{array}$ & \\
\hline Cartham & & & & & & & & & \\
\hline $\begin{array}{l}\text { us } \\
\text { tinctoriu }\end{array}$ & $\begin{array}{l}1536 \\
75\end{array}$ & $\begin{array}{l}836 \\
06\end{array}$ & $\begin{array}{l}254 \\
07\end{array}$ & $\begin{array}{l}191 \\
56\end{array}$ & 37.4 & 89 & 4 & 30 & $\begin{array}{l}\text { KX8220 } \\
74\end{array}$ \\
\hline Ageratin & & & & & & & & & \\
\hline $\begin{array}{l}\text { a } \\
\text { adenoph } \\
\text { ora }\end{array}$ & $\begin{array}{l}1506 \\
89\end{array}$ & $\begin{array}{l}848 \\
15\end{array}$ & $\begin{array}{l}237 \\
55\end{array}$ & $\begin{array}{l}183 \\
58\end{array}$ & 37.5 & 80 & 4 & 28 & $\begin{array}{l}\text { JF } 82650 \\
3\end{array}$ \\
\hline $\begin{array}{l}\text { Guizotia } \\
\text { abyssinic } \\
a\end{array}$ & $\begin{array}{l}1506 \\
89\end{array}$ & $\begin{array}{l}828 \\
55\end{array}$ & $\begin{array}{l}247 \\
77\end{array}$ & $\begin{array}{l}182 \\
77\end{array}$ & 37.3 & 79 & 4 & 29 & $\begin{array}{l}\text { HQ2346 } \\
69\end{array}$ \\
\hline $\begin{array}{l}\text { Lactuca } \\
\text { sativa }\end{array}$ & $\begin{array}{l}1527 \\
72\end{array}$ & $\begin{array}{l}841 \\
05\end{array}$ & $\begin{array}{l}250 \\
34\end{array}$ & $\begin{array}{l}185 \\
99\end{array}$ & 37.5 & 78 & 4 & 20 & $\begin{array}{l}\text { DQ3838 } \\
16\end{array}$ \\
\hline Helianth & & & & & & & & & \\
\hline $\begin{array}{l}\text { us } \\
\text { tuberosu }\end{array}$ & $\begin{array}{l}1514 \\
31\end{array}$ & $\begin{array}{l}839 \\
81\end{array}$ & $\begin{array}{l}245 \\
68\end{array}$ & $\begin{array}{l}182 \\
79\end{array}$ & 37.6 & 84 & 4 & 27 & $\begin{array}{l}\text { MG6966 } \\
58\end{array}$ \\
\hline Helianth & & & & & & & & & \\
\hline $\begin{array}{l}\text { us } \\
\text { argophyl } \\
\text { lus }\end{array}$ & $\begin{array}{l}1518 \\
62\end{array}$ & $\begin{array}{l}838 \\
45\end{array}$ & $\begin{array}{l}245 \\
88\end{array}$ & $\begin{array}{l}181 \\
49\end{array}$ & 37.6 & 80 & 4 & 27 & $\begin{array}{l}\text { KU3145 } \\
00\end{array}$ \\
\hline $\begin{array}{l}\text { Helianth } \\
\text { us debilis }\end{array}$ & $\begin{array}{l}1516 \\
78\end{array}$ & $\begin{array}{l}837 \\
99\end{array}$ & $\begin{array}{l}245 \\
02\end{array}$ & $\begin{array}{l}181 \\
21\end{array}$ & 37.6 & 82 & 4 & 27 & $\begin{array}{l}\text { KU3129 } \\
28\end{array}$ \\
\hline Helianth & & & & & & & & & \\
\hline $\begin{array}{l}\text { us } \\
\text { petiolari } \\
\text { s subsp. } \\
\text { fallax }\end{array}$ & $\begin{array}{l}1511 \\
04\end{array}$ & $\begin{array}{l}835 \\
30\end{array}$ & $\begin{array}{l}246 \\
33\end{array}$ & $\begin{array}{l}183 \\
08\end{array}$ & 37.6 & 79 & 4 & 27 & $\begin{array}{l}\text { KU2955 } \\
60\end{array}$ \\
\hline
\end{tabular}




\section{Table 5 (on next page)}

Table 5 Likelihood ratio statistics of positive selection models against their null models ( $2 \Delta \ln \mathrm{L})$ 
1 Table 5 Likelihood ratio statistics of positive selection models against their null models ( $2 \Delta$ $2 \ln \mathbf{L})$

\begin{tabular}{llll}
\hline $\begin{array}{l}\text { Comparison between } \\
\text { models }\end{array}$ & $2 \Delta \ln \mathrm{L}$ & d.f. & P-value \\
\hline M0 vs. M3 & 15.2245 & 4 & $0.0043<0.01$ \\
M1a vs. M2a & 13.5353 & 2 & $0.0012<0.01$ \\
M7 vs. M8 & 15.0177 & 2 & $0.0005<0.01$ \\
M8a vs. M8 & 13.5241 & 1 & $0.0002<0.01$ \\
\hline
\end{tabular}

3 


\section{Table 6(on next page)}

Table 6 Positive selective amino acid loci and parameter estimation in ycf2 of 8 species in the compositae family species. 
1 Table 6 Positive selective amino acid loci and parameter estimation in ycf 2 of 8 species in

2 the compositae family species.

\begin{tabular}{|c|c|c|c|c|c|}
\hline Models & $N p$ & $\ln L$ & $\begin{array}{l}\text { Estimates of } \\
\text { parameters }\end{array}$ & $\begin{array}{l}\text { Positive sites } \\
\text { (NEB) }\end{array}$ & $\begin{array}{l}\text { Positive sites } \\
(B E B)\end{array}$ \\
\hline M0(one-ratio) & 15 & -9464.31 & $\omega=0.93903$ & Not allowed & Not allowed \\
\hline \multirow[t]{7}{*}{ M3(Discrete) } & \multirow[t]{7}{*}{19} & \multirow[t]{7}{*}{-9456.70} & $p_{0}=0.00005$ & $1125 \mathrm{~W} 0.602$ & \multirow[t]{7}{*}{ Not allowed } \\
\hline & & & \multirow{2}{*}{$\omega_{0}=0.07668$} & 1238G 0.779 & \\
\hline & & & & $1239 \mathrm{~N} 0.980^{*}$ & \\
\hline & & & $p_{1}=0.99613$, & 1476F 0.649 & \\
\hline & & & $\omega_{1}=0.86440$ & \multirow[t]{3}{*}{ 1518R 0.992** } & \\
\hline & & & $p_{2}=0.00382$, & & \\
\hline & & & $\omega_{2}=43.87141$ & & \\
\hline \multirow{2}{*}{$\begin{array}{l}\text { M1a(Near } \\
\text { neutral) }\end{array}$} & \multirow[t]{2}{*}{16} & \multirow[t]{2}{*}{-9463.47} & $p_{0}=0.20671, \omega_{0}=0$ & \multirow[t]{2}{*}{ Not allowed } & \multirow[t]{2}{*}{ Not allowed } \\
\hline & & & $p_{1}=0.79329, \omega_{1}=1$ & & \\
\hline \multirow[t]{7}{*}{ M2a(Selection) } & \multirow[t]{7}{*}{18} & \multirow[t]{7}{*}{-9456.70} & \multirow[t]{3}{*}{$p_{0}=0.98950$} & $1125 \mathrm{~W} 0.602$ & $331 \mathrm{I} 0.726$ \\
\hline & & & & 1238G 0.779 & $662 \mathrm{~K} 0.727$ \\
\hline & & & & $1239 \mathrm{~N} 0.980 *$ & $1125 \mathrm{~W} 0.677$ \\
\hline & & & \multirow[t]{3}{*}{$p_{1}=0.00668, \omega_{1}=1$} & \multirow{3}{*}{$\begin{array}{l}\text { 1476F } 0.649 \\
1518 \mathrm{R} 0.992 * *\end{array}$} & 1238G 0.770 \\
\hline & & & & & $1239 \mathrm{~N} 0.940$ \\
\hline & & & & & 1476F 0.759 \\
\hline & & & $\omega_{2}=43.84482$ & & 1518R 0.950* \\
\hline \multirow[t]{2}{*}{ M7(beta) } & \multirow[t]{2}{*}{16} & \multirow[t]{2}{*}{-9464.36} & $p=0.50360$ & \multirow[t]{2}{*}{ Not allowed } & \multirow[t]{2}{*}{ Not allowed } \\
\hline & & & $q=0.00500$ & & \\
\hline \multirow[t]{8}{*}{ M8(beta \& $\omega)$} & \multirow[t]{8}{*}{18} & \multirow[t]{8}{*}{-9460.27} & $p_{0}=0.66725$ & $1125 \mathrm{~W} 0.600$ & 331I 0.882 \\
\hline & & & $p=0.00500$ & 1238G 0.778 & $662 \mathrm{~K} 0.823$ \\
\hline & & & $p_{1}=0.33275$ & $1239 \mathrm{~N} 0.980^{*}$ & $1095 \mathrm{~S} 0.526$ \\
\hline & & & $q=1.20677$ & $1476 \mathrm{~F} 0.647$ & $1125 \mathrm{~W} 0.774$ \\
\hline & & & \multirow{4}{*}{$\omega=2.95373$} & \multirow[t]{4}{*}{ 1518R 0.991** } & $1238 \mathrm{G} 0.851$ \\
\hline & & & & & $1239 \mathrm{~N} 0.965^{*}$ \\
\hline & & & & & 1476F 0.844 \\
\hline & & & & & 1518R 0.971* \\
\hline M8a(beta & 17 & -9463.50 & $p_{0}=0.21119$ & Not allowed & Not allowed \\
\hline
\end{tabular}




$p=3.03780$
$p_{1}=0.78881$,
$q=1.57211$
$\omega=1$

3 Positively selected sites (*: $\mathrm{P}>95 \%$; **: $\mathrm{P}>99 \%$ )

4 


\section{Figure 1}

Figure 1 Gene map of the Helianthus tuberosus L. chloroplast genome.

Genes drawn outside of the circle are transcribed counter-clockwise, while genes shown on the inside of the circle are transcribed clockwise. Genes belonging to different functional groups are color-coded. The darker gray in the inner circle indicates GC content, while the lighter gray corresponds to AT content. 


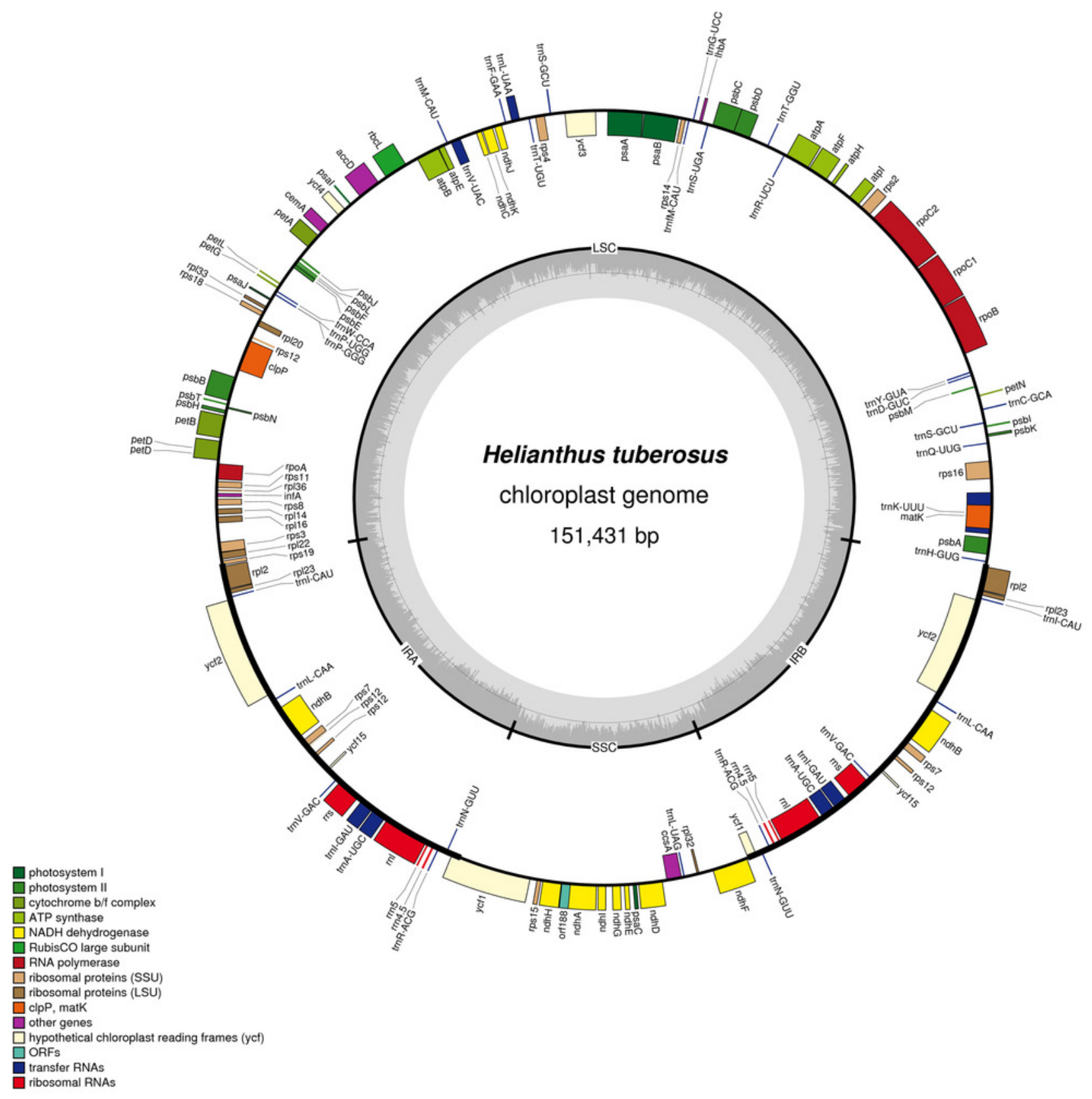


Figure 2

Figure 2 Distribution frequency in Helianthus tuberosus L. cp genome.

A: The frequency of repeats, length of repeats; Number of repeats. B: The percentage distribution of gene area. 


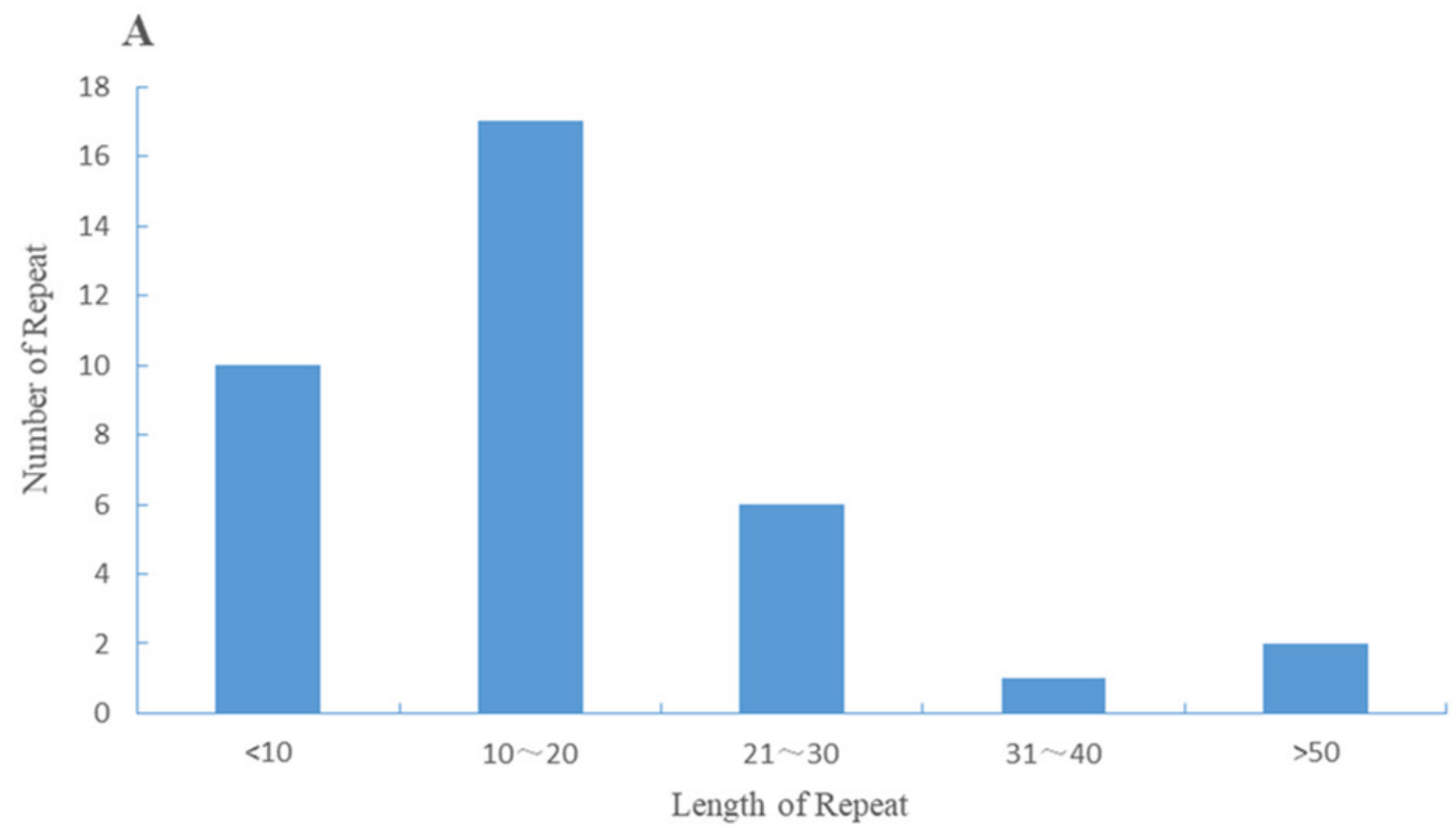

B

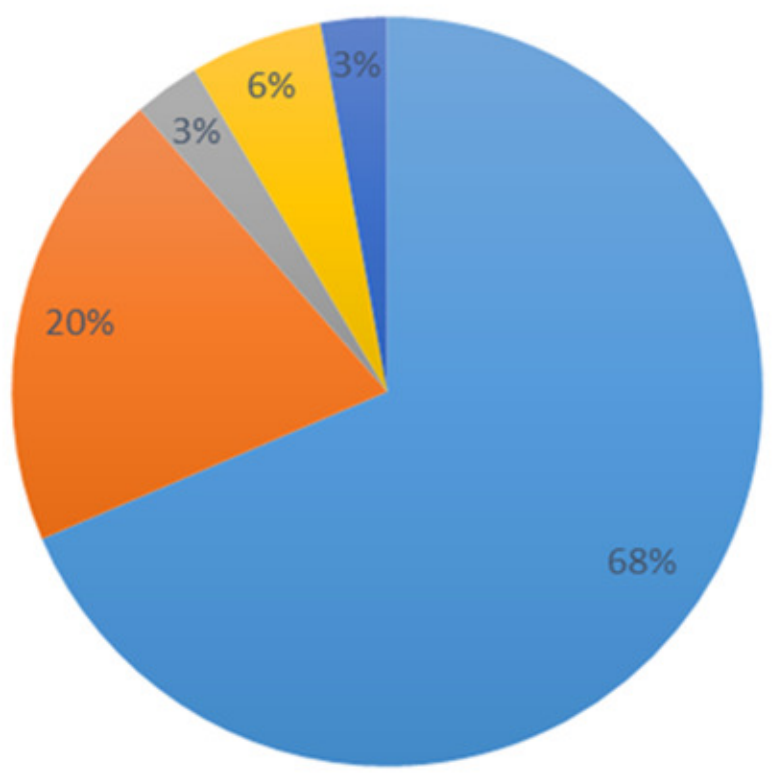

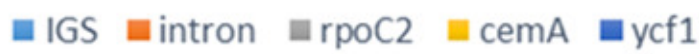


Figure 3

Figure 3 Distribution frequency in Helianthus tuberosus L. cp genome.

A: The frequency of repeats, length of repeats; Number of repeats. B: The percentage distribution of gene area.

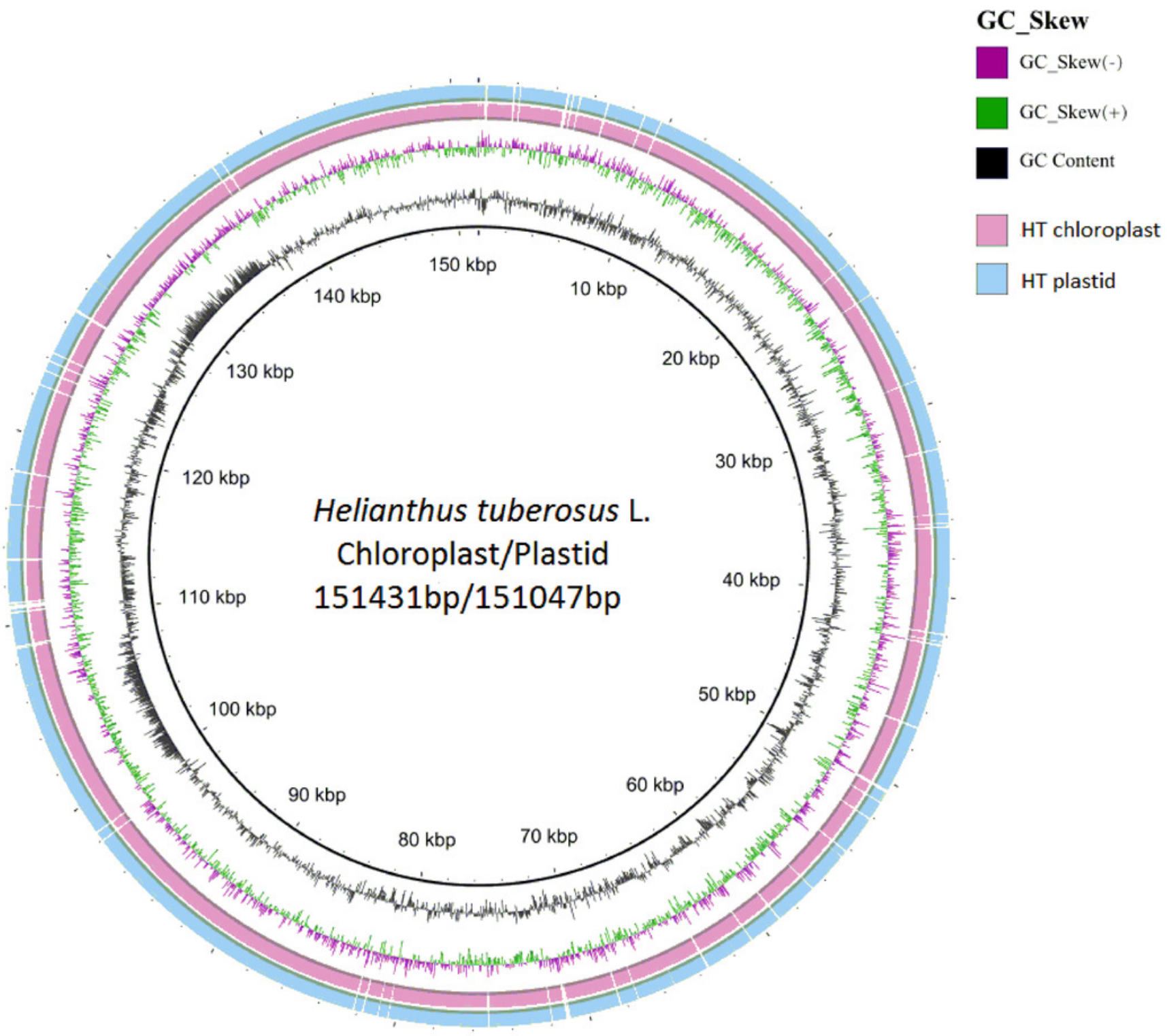




\section{Figure 4}

Figure 4 Percent identity plot for the comparison of 8 composite chloroplast genomes.

The whole chloroplast genome was divided into four parts, and the gene names are displayed in sequence on the top line of each part (arrows indicate the transcriptional direction). The sequence similarity of the alignment region of Jerusalem artichoke and seven other species is shown as the filling color in each black stripe. The $\mathrm{x}$-axis indicates the position of the chloroplast genome at a certain site, and the $y$-axis indicates the average sequence identity percentage (50-100\%) with Jerusalem artichoke on the position of a species at a certain position (50-100\%). The coding sequences (exons), rRNA, tRNA and the conserved noncoding sequences (CNS) in the genomic region are represented with different colors. 


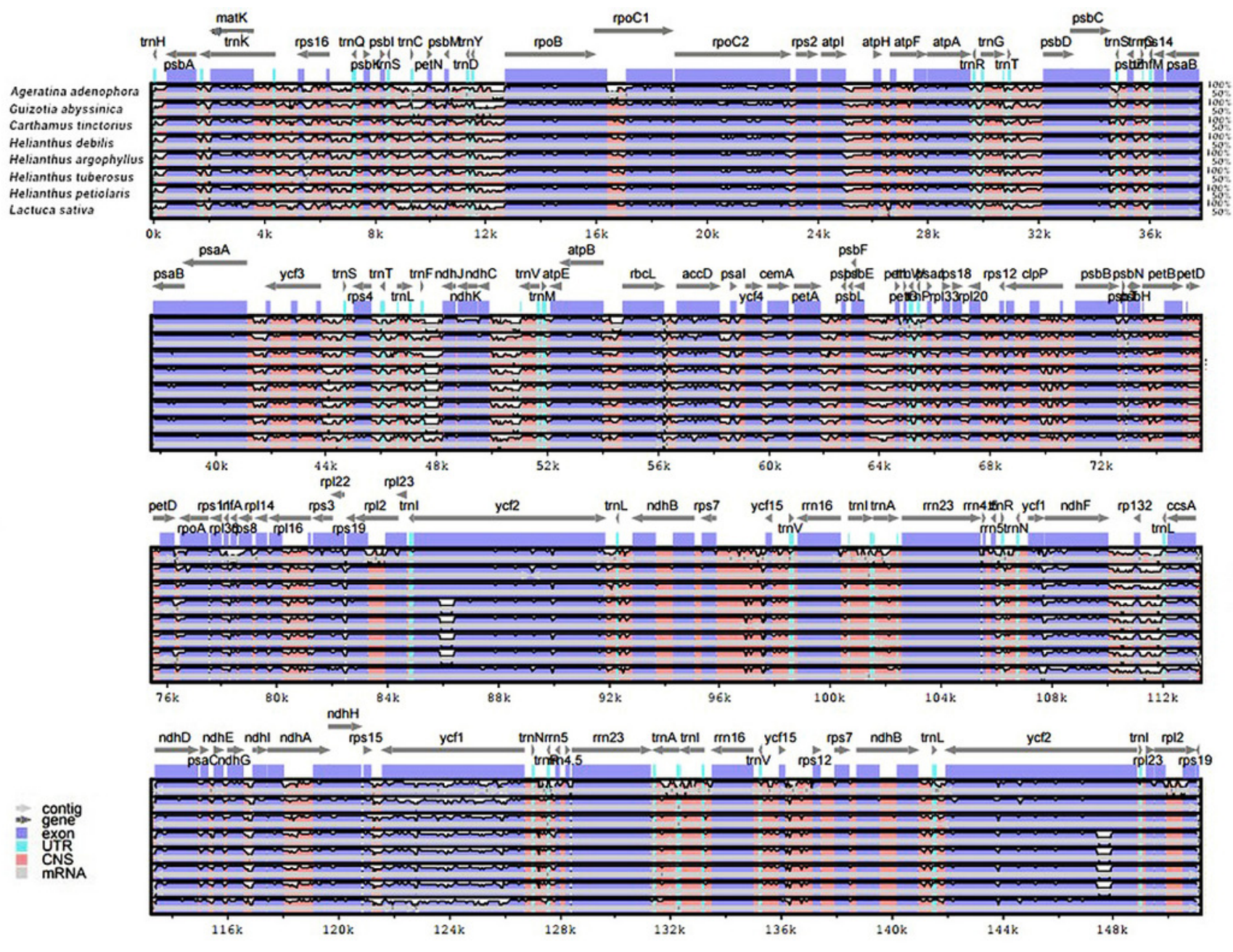




\section{Figure 5}

Figure 5. Comparison of the similarity of chloroplast genomes between Jerusalem artichoke and seven other species of crops in the composite family.

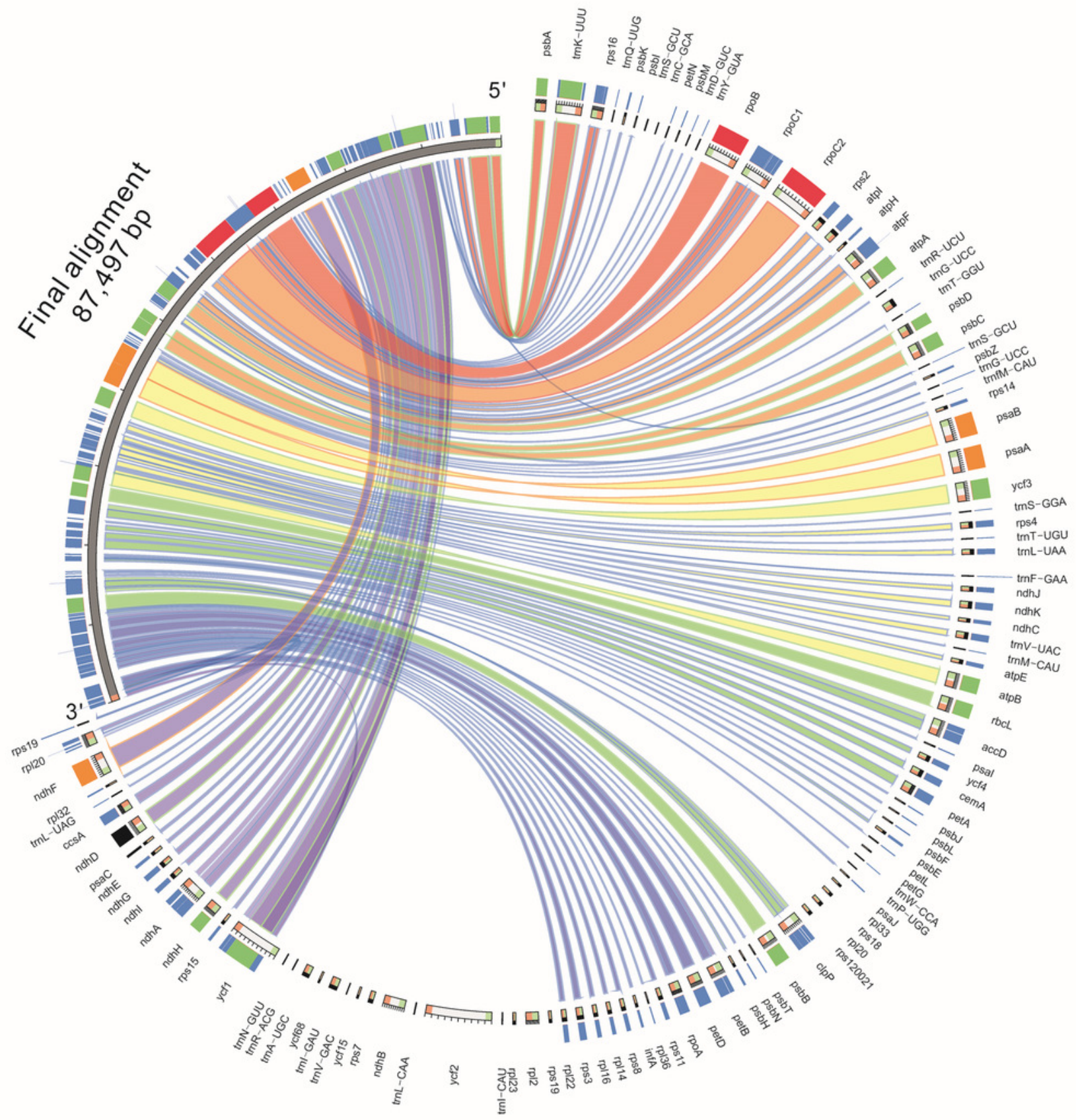


Figure 6

Figure 6. Comparison of the ycf2 gene sequence in chloroplast genomes between Jerusalem artichoke and seven other species of crops in the composite family.

The white vacancy corresponds to the missing amino acid sequence.

\begin{tabular}{|c|c|c|c|c|c|c|c|c|c|c|c|c|c|c|}
\hline Sequence ID & Start & 200 & 400 & 600 & 800 & 1000 & 1200 & 1400 & 1600 & 1800 & 2000 & 2200 & End & Organism \\
\hline \begin{tabular}{|l} 
AEG64601.1 \\
\end{tabular} & $\approx 1$ & & & & & & & 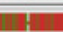 & & & & If & 2,248 & Ageratina adenoohora \\
\hline \begin{tabular}{|l|} 
YP001837404.1 \\
\end{tabular} & $\approx 1$ & & & & & & & & & & & & 2,276 & Guizotia abyssinica \\
\hline \begin{tabular}{|l|} 
YP398372.1 \\
\end{tabular} & $\approx 1$ & $=$ & & & & & & 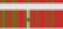 & & & & - & 2,264 & Lactuca sativa \\
\hline APD83382.1 & \pm 1 & E & & & & & & & & & & & 2,291 & Carthamus tinctorius \\
\hline \begin{tabular}{|l|} 
ANA91252.1 \\
\end{tabular} & $\Sigma 1$ & & & & & & & & & & & 7 & 2,131 & Helianthus debilis \\
\hline \begin{tabular}{|l|} 
ANF03726.1 \\
\end{tabular} & $\frac{1}{1}$ & & & & & & & & & & & & 2,129 & Helianthus argoolyillus \\
\hline \begin{tabular}{|l|} 
AMQ33980.1 \\
\end{tabular} & $=1$ & & & & & & & & & & & & 2,119 & Hellianthus_petiolaris \\
\hline \begin{tabular}{|l|} 
AVN90116.1 \\
\end{tabular} & $=1$ & & & & & & & & & & & & 2,131 & $\begin{array}{l}\text { Helianthus tuberosus } \\
\end{array}$ \\
\hline
\end{tabular}


Figure 7

Figure 7. Molecular phylogenetic tree of 16 composite species based on a neighbor joining analysis.

Numbers above and below nodes are bootstrap support values $50 \%$.

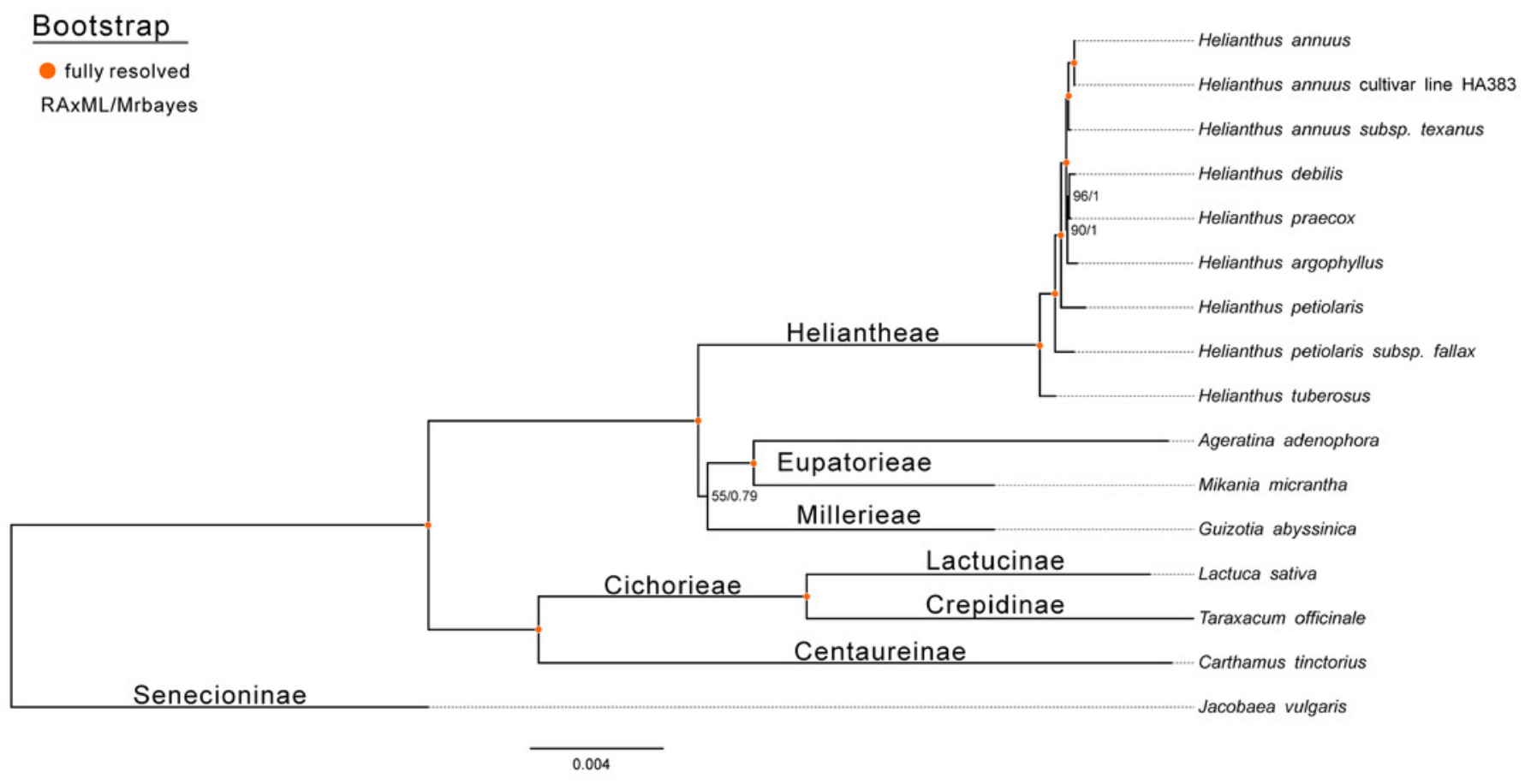

